\title{
The Water Decomposition Reactions on Boron-Doped Diamond Electrodes
}

\author{
Hugo B. Suffredini, Sérgio A. S. Machado and Luis A. Avaca* \\ Instituto de Química de São Carlos, Universidade de São Paulo, CP 780, 13560-970 São Carlos - SP, Brazil
}

\begin{abstract}
As reações eletródicas que ocorrem em ambos extremos da extensa janela eletroquímica do eletrodo de diamante dopado com boro foram analisadas por curvas de polarização visando determinar as respectivas energias de ativação aparentes para a etapa determinante da velocidade em cada caso. Encontrou-se que a reação de desprendimento de hidrogênio ocorre por um mecanismo VolmerHeyrovsky, com a primeira etapa sendo a determinante da velocidade. A energia de ativação aparente foi calculada como sendo $150 \mathrm{~kJ} \mathrm{~mol}^{-1}$, indicando a formação de um intermediário do tipo M-H, típico da etapa de Volmer. Por outro lado, a energia de ativação aparente para a reação de desprendimento de oxigênio foi encontrada como sendo $106 \mathrm{~kJ} \mathrm{~mol}^{-1}$, o que também indica a etapa de adsorção do mecanismo como a determinante da velocidade. Desta forma, demonstrou-se que a interação entre as moléculas de água e a superfície do eletrodo de diamante é fortemente inibida, o que explica a extensa janela de potenciais observada para este eletrodo.
\end{abstract}

The electrochemical processes occurring at both edges of the wide electrochemical window of the boron doped diamond (BDD) electrode were studied by polarization curves experiments to evaluate the apparent energy of activation for the rate determining step in each reaction. It was found that the hydrogen evolution reaction occurs by a Volmer-Heyrovsky mechanism with the first step being the RDS. Moreover, the apparent energy of activation calculated from the Tafel plots presented a value as high as $150 \mathrm{~kJ} \mathrm{~mol}^{-1}$, indicating the formation of the $\mathrm{M}-\mathrm{H}$ intermediate that is characteristic for the Volmer step. On the other hand, the apparent energy of activation for the oxygen evolution reaction was found to be $106 \mathrm{~kJ} \mathrm{~mol}^{-1}$ suggesting that the RDS in this mechanism is the initial adsorption step. In this way, it was demonstrated that the interaction between water molecules and the electrode surface is strongly inhibited on BDD thus justifying the extended potential window observed for this material.

Keywords: boron-doped diamond electrode, hydrogen evolution reaction, oxygen evolution reaction, water decomposition

\section{Introduction}

\section{Diamond and diamond films}

The relation between man and diamond has always been a history of interest and fascination since this is an exotic and rare material that possesses a very high commercial value. Diamond is an allotropic form of carbon whose uniqueness is related with the high atomic density, extreme hardness and mechanical resistance. Moreover, its enhanced stability against chemical degradation makes it a singularly inert material.

Being an electric isolating material, diamond failed to have the necessary characteristics to be useful as an electrode material in electrochemical devices. Therefore,

* e-mail: avaca@iqsc.usp.br its utilization in the electrochemistry field has scarcely been brought into attention. Meanwhile, this situation began to change when the technological aspects for the production of thin films of synthetic diamonds from gas phase reagents become available. This was achieved by the Chemical Vapor Deposition (CVD) technique. ${ }^{1,2}$ During the eighties, Terometskaya et al. made important contributions to this field by performing deposition studies with a vapor-phase composed of volatile organic compounds and inorganic gases such as hydrogen. ${ }^{3}$

The CVD technique is continuously being improved by studies of new vapor-phases and design of new reactors. Such evolution has allowed its use nowadays for the deposition of ultra-thin films of boron-doped diamond (BDD) on different substrates. As the proper name states, boron is the doping element usually incorporated from gaseous trimethyl-boron, in a concentration range between 
10 and 10,000 ppm. The insertion of such doping material yields semi-conducting or semi-metal properties to the diamond deposit, which are always dependent on the doping agent concentration. ${ }^{4}$ Thus, boron concentrations in the order of $10^{18}$ atoms $\mathrm{cm}^{-3}$ determine a film resistance of approximately $10^{4} \Omega$ while increasing the boron content to $10^{21}$ atoms $\mathrm{cm}^{-3}$ the resistance diminishes to $10^{-2} \Omega .{ }^{5} \mathrm{In}$ the deposition of the diamond film, the carbon source can be methane, methanol, acetone or any other volatile organic compound. Usually methane is chosen for its availability and because it fulfills all the requirements for a good CVD deposition. A 1998 study carried out by Fisher et al. discussed the present-day possibility of obtaining a BDD layer on a variety of substrates. ${ }^{6}$ The characterization of BDD films is usually performed by Atomic Force Microscopy (AFM) for the analysis of surface topology and by Raman Spectroscopy for the quantification of $s p^{3}$ and $s p^{2}$ carbon phases, both formed in the final part of the CVD process. ${ }^{?}$

BDD electrodes possess electrochemical properties significantly different from other allotropic forms of carbon that are used as electrode materials, such as pyrolytic graphite and vitreous carbon. It shows a very large electrochemical potential window in either aqueous or nonaqueous media, ${ }^{8-10}$ enhanced chemical and mechanical stability and high corrosion resistance. ${ }^{11,12}$ The BDD electrode is not extensively modified by anodic polarizations with current densities as high as $2-10 \mathrm{~A} \mathrm{~cm}^{-2}$ during a few weeks, ${ }^{13}$ in a clear contrast with the other carbon electrodes. Due to its special properties, the BDD films were initially of great interest to the micro-informatic industry for the manufacturing of computer chips and to the electronic industry for the production of several electronic components. ${ }^{14}$

Formally, the first electrochemical report concerning diamond modifications was published by Iwaki et al. in 1983 when they proposed to produce a diamond dielectric crystal with the insertion of argon ions $\left(\mathrm{Ar}^{+}\right),{ }^{15}$ in a chemical vapor deposition process. It was further discovered that $\mathrm{Ar}^{+}$was not a real doping impurity but was acting only in the process of destruction of the crystalline array of pure diamond.

Due to the extended electrochemical window observed between the hydrogen and the oxygen evolution reactions in aqueous medium as well as the very low capacitive currents, the BDD electrode has several applications, mainly in electroanalysis. Recent work from this laboratory has shown the effectiveness of this material for the analytical determination of pentaclorophenol in pure and contaminated waters by square wave voltammetry. ${ }^{16,17}$ Moreover, studies of the oxidation of pentachlorophenol as a function of the electrode potential have been also performed. ${ }^{18}$ It was found that at very large positive potentials the total combustion of this pesticide could be achieved with high efficiency. Therefore, the study of the processes occurring at the limits of potential stability of water on BDD electrodes becomes an important subject for the understanding of the electrochemical behavior of that surface.

The fabrication and initial characterization of a diamond coated quartz crystal microbalance electrode has been recently reported by Zhang et al. ${ }^{19}$ In that work, the mass sensitivity of the system was determined by iron electrodeposition. The wide potential window and the significantly low background current measured there are practically the same as those of a conventional diamond electrode suggesting several future applications for the new device.

Pastor-Moreno and Riley studied the reduction on BDD of 1,4-benzoquinone dissolved in acetonitrile. ${ }^{20}$ The cyclic voltammograms obtained suggest that the sub-surface hydrogen present in the hydrogenated diamond lattice is able to participate in electrochemical processes.

The electrochemical behavior of as-deposited diamond was examined in various non-aqueous solvents and supporting electrolytes by Yoshimura et al. The potential for the onset of anodic current was found to be dependent on the nature of the organic solvent, whereas that for the onset of cathodic current was dependent on the type of supporting electrolyte cation. ${ }^{21}$ These results indicate that outer-sphere decomposition reactions of the organic solvents are the most important in determining the oxidation potential limit while those involving cations are the most important in determining the reduction potential limit.

\section{The water decomposition reactions}

It is well established that the hydrogen evolution reaction (HER) in acid media occurs through an overall mechanism composed by an association of two or even three of the following reactions where $\mathrm{S}$ represents a site on the electrode surface:

$$
\begin{aligned}
& \mathrm{S}+\mathrm{H}^{+}+\mathrm{e}^{-} \leftrightarrows \mathrm{SH} \\
& \mathrm{SH}+\mathrm{H}^{+}+\mathrm{e}^{-} \rightarrow \mathrm{S}+\mathrm{H}_{2} \\
& \mathrm{SH}+\mathrm{SH} \rightarrow 2 \mathrm{~S}+\mathrm{H}_{2}
\end{aligned}
$$

Volmer reaction (1)

Heyrovsky reaction (2)

Tafel reaction (3)

On active cathodes, such as $\mathrm{Ni}, \mathrm{Fe}$ and their alloys in alkaline medium, the reaction mechanism is simplified to the Volmer and Heyrovsky reactions, with the second one being the rate determining step (RDS). Under such 
conditions, the apparent energy of activation, $\Delta \mathrm{G}^{\#}$, is often measured as $\sim 50 \mathrm{~kJ} \mathrm{~mol}^{-1}$, a value related to the formation of the following activated complex: ${ }^{22}$

$$
[\mathrm{SH}-\mathrm{-}-\mathrm{H}]^{+} \quad \Delta \mathrm{G}^{\#} \sim 50 \mathrm{~kJ} \mathrm{~mol}^{-1}(4)
$$

Differently, on non-active materials such as $\mathrm{Hg}$ in acid medium, the Volmer reaction is the RDS and the activation energy has been calculated as approximately $200 \mathrm{~kJ} \mathrm{~mol}^{-1}$ and related to the formation of: ${ }^{23}$

$$
[\mathrm{S}-\mathrm{-H}]^{+} \quad \Delta \mathrm{G}^{\#} \sim 200 \mathrm{~kJ} \mathrm{~mol}^{-1}(5)
$$

On the other hand, the oxygen evolution reaction (OER) can be represented by the following simplified mechanism:

$$
\begin{aligned}
& \mathrm{S}+\mathrm{H}_{2} \mathrm{O} \leftrightarrows \mathrm{S}-\mathrm{OH}+\mathrm{H}^{+}+\mathrm{e}^{-} \\
& \mathrm{S}-\mathrm{OH} \leftrightarrows \mathrm{S}-\mathrm{O}+\mathrm{H}^{+}+\mathrm{e}^{-} \\
& 2 \mathrm{~S}-\mathrm{O} \rightarrow 2 \mathrm{~S}+\mathrm{O}_{2}
\end{aligned}
$$

where the first electron transfer step [equation 6] is the RDS. A value of $47 \mathrm{~kJ} \mathrm{~mol}^{-1}$ has been published for the apparent energy of activation $\left(\Delta \mathrm{G}^{\#}\right)$ of this step in acid medium and onto activated anodes (e.g., Pt). ${ }^{24}$

On BDD electrodes both the oxygen and the hydrogen evolution reactions occur at very high overpotentials suggesting that the adsorption of intermediate species is very difficult on such surface. Therefore, the objective of this work is the study of the water decomposition reactions on the boron doped diamond electrode in acid media to try to establish the corresponding mechanisms and the reasons for the lack of electrocatalytic activity of such peculiar surface. The studies have been carried out at both the cathodic and anodic potential limits of the electrochemical window in aqueous medium by steady state polarization curves at different temperatures.

\section{Experimental}

The electrochemical experiments were performed in a Pyrex $^{\circledR}$ glass cell provided with three electrodes and degassing facilities for bubbling $\mathrm{N}_{2}$. The reference electrode was the hydrogen system in the same solution (HESS) and the auxiliary one was a $2 \mathrm{~cm}^{2} \mathrm{Pt}$ foil. The working electrode was a $0.62 \times 1.0 \mathrm{~cm}$ boron doped diamond film deposited on a silicon wafer kindly furnished by Eng. W. Haenni of the Centre Suisse de Electronique et de Microtechnique SA (CSEM), Neuchatêl, Switzerland. This material was prepared at CSEM using the hot filament chemical vapor deposition (HF-CVD) technique with a filament temperature in the range $2440-2560{ }^{\circ} \mathrm{C}$ and a gaseous mixture containing methane, $\mathrm{H}_{2}$ and trimethylboron. The final boron content was of the order of 4500-5000 ppm. The reagents used in this work were all of Merck P.A. quality and the water was purified by the Milli-Q system from Millipore.

Steady-state polarization curves for the hydrogen and the oxygen evolution reactions were carried out in $0.5 \mathrm{~mol} \mathrm{~L}^{-1} \mathrm{Na}_{2} \mathrm{SO}_{4}+0.5 \mathrm{~mol} \mathrm{~L}^{-1} \mathrm{H}_{2} \mathrm{SO}_{4}$ solutions in the temperature range of $25-65^{\circ} \mathrm{C}$, controlled by a thermostatic bath. All electrochemical experiments were carried out using a Mod. 283 EG\&G PARC electrochemical instrument. To improve the reproducibility of the experiments, the BDD electrode was subjected to a cathodic polarization at $-0.8 \mathrm{~V}$ for $120 \mathrm{~s}$ in a $0.5 \mathrm{~mol} \mathrm{~L}^{-1} \mathrm{H}_{2} \mathrm{SO}_{4}$ solution prior to the measurements.

\section{Results and Discussion}

The steady-state voltammetric response of the BDD electrode in a $0.5 \mathrm{~mol} \mathrm{~L}^{-1} \mathrm{H}_{2} \mathrm{SO}_{4}$ solution at $0.1 \mathrm{~V} \mathrm{~s}^{-1}$ is shown in curve (a) of Figure 1. The existence of a wide potential window ranging from $-0.75 \mathrm{~V}$ to $2.35 \mathrm{~V} v s$ HESS can be observed. This extended interval, allied with the extremely low capacitive currents also observed, makes the BDD one of the most suitable electrodes for analytical applications. As a consequence, the number of papers available in that field is high and increasing continuously. However, the knowledge on why the electrochemical reactions occurring at the potential edges in aqueous media are so strongly inhibited is very important for the understanding of the full range of possible applications for the BDD electrode.

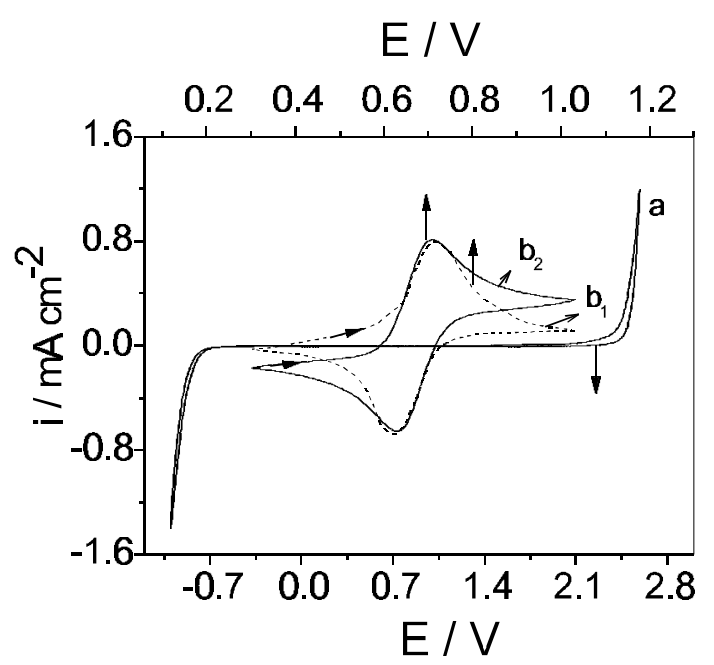

Figure 1. Steady-state voltammetric response of the BDD electrode in $0.5 \mathrm{~mol} \mathrm{~L}^{-1} \mathrm{H}_{2} \mathrm{SO}_{4}$ (a) and $1^{\text {st }}$ scan voltammograms in $10^{-3} \mathrm{~mol} \mathrm{~L}^{-1}$ $\mathrm{K}_{4} \mathrm{Fe}(\mathrm{CN})_{6}+0.5 \mathrm{~mol} \mathrm{~L}^{-1} \mathrm{H}_{2} \mathrm{SO}_{4}$ for the BDD $\left(\mathrm{b}_{1}\right)$ and the Pt electrodes $\left(\mathrm{b}_{2}\right) . v=0.1 \mathrm{~V} \mathrm{~s}^{-1}$. 
The roughness factor of the BDD electrode was initially determined by comparison of the $1^{\text {st-cycle }}$ voltammetric response in a solution containing $10^{-3} \mathrm{~mol} \mathrm{~L}^{-1} \mathrm{~K}_{4} \mathrm{Fe}(\mathrm{CN})_{6}+$ $0.5 \mathrm{~mol} \mathrm{~L}^{-1} \mathrm{Na}_{2} \mathrm{SO}_{4}$ with that obtained on a Pt electrode. This is also shown in Figure 1 (curves $b_{1}$ and $b_{2}$, respectively). For the Pt electrode (geometric area of 0.12 $\left.\mathrm{cm}^{2}\right)$, the electrochemical active area $\left(0.175 \mathrm{~cm}^{2}\right)$ was previously established through a measurement of the voltammetric $\mathrm{H}$-adsorption charge in $\mathrm{H}_{2} \mathrm{SO}_{4}$ solutions. As a result of these experiments, a roughness factor of 1.6 was determined for the BDD electrode that, in turn, means that its active area was practically equal to $1 \mathrm{~cm}^{2}$.

\section{The Hydrogen Evolution Reaction}

To analyze the faradic reaction occurring at the cathodic edge of the potential window of BDD, steady-state polarization curves were recorded at several temperatures using the galvanostatic mode. Thus, a constant cathodic current density in the range $10^{-3}$ to $10^{-1} \mathrm{~A} \mathrm{~cm}^{-2}$ was imposed to the electrode and the corresponding potential measured after stabilization. The electrode potential values were corrected for the ohmic drop contribution with the Current Interrupt tool available in the electrochemical device used here. The results obtained are presented in Figure 2 in the form of the traditional Tafel plots.

The slopes obtained from the straight lines in Figure 2 varied between 135 and $159 \mathrm{mV} \mathrm{dec}^{-1}$. Extrapolation to $\eta=0$ allowed the calculation of the exchange current density value $\left(i_{0}\right)$ for each temperature. These values were used to construct the Arrhenius plot presented in Figure 3 from which the apparent energy of activation, $\Delta \mathrm{G}^{\#}$, was calculated. All these parameters for the HER are collected in Table 1.

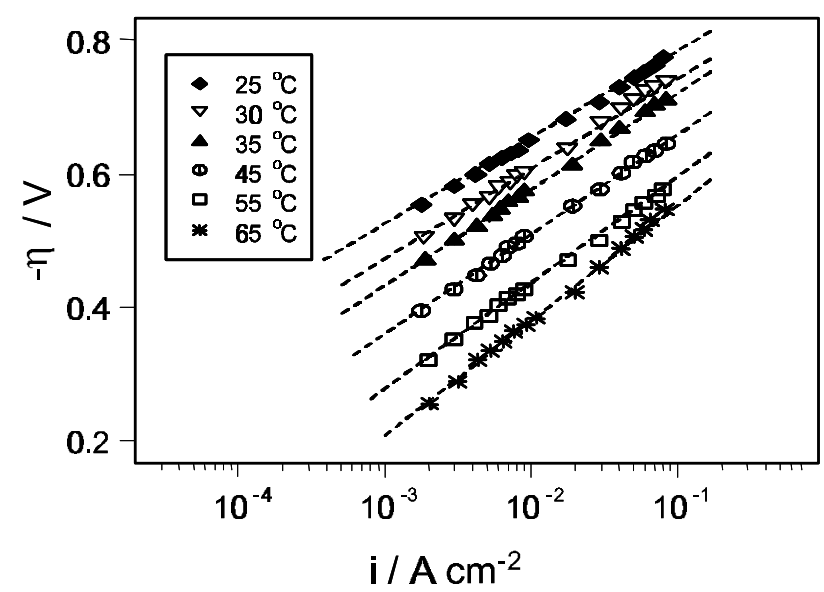

Figure 2. Tafel plots for the HER on the BDD electrode in $0.5 \mathrm{~mol} \mathrm{~L}^{-1}$ $\mathrm{H}_{2} \mathrm{SO}_{4}+0.5 \mathrm{~mol} \mathrm{~L}^{-1} \mathrm{Na}_{2} \mathrm{SO}_{4}$ at different temperatures.

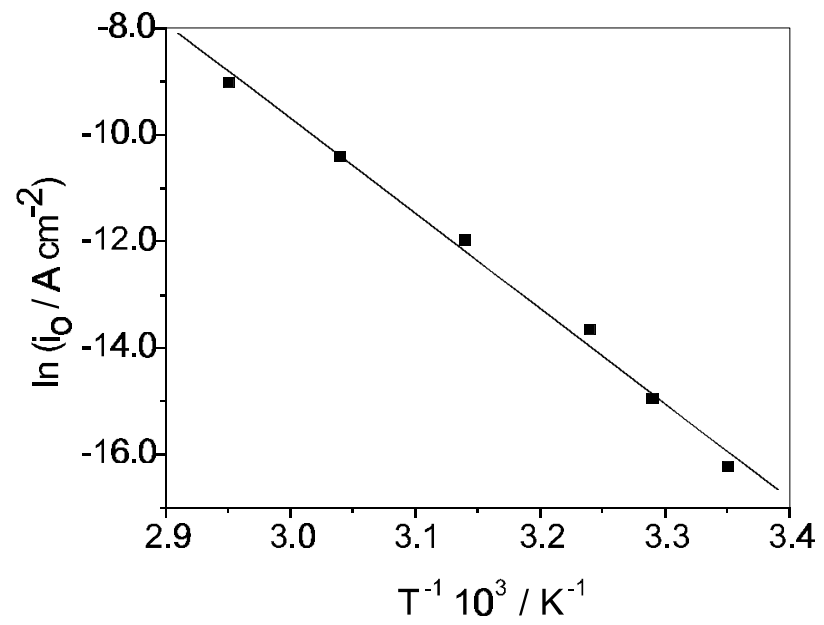

Figure 3. Arrhenius plot for the HER on the BDD electrode with data taken from Figure 2.

Table 1. Tafel parameters for the HER on the BDD electrode in acid media

\begin{tabular}{cccc}
\hline $\mathrm{T} /{ }^{\circ} \mathrm{C}$ & $\mathrm{b}_{\exp } / \mathrm{mV} \mathrm{dec}^{-1}$ & $\mathrm{i}_{\mathrm{o}} / \mathrm{A} \mathrm{cm}^{-2}$ & $\Delta \mathrm{G}^{\# / \mathrm{kJ} \mathrm{mol}^{-1}}$ \\
\hline 25 & 135 & $9.08 \times 10^{-8}$ & \\
30 & 145 & $3.21 \times 10^{-7}$ & \\
35 & 148 & $1.18 \times 10^{-6}$ & 150 \\
45 & 151 & $6.32 \times 10^{-6}$ & \\
55 & 156 & $3.06 \times 10^{-5}$ & \\
65 & 159 & $1.20 \times 10^{-4}$ & \\
\hline
\end{tabular}

The Tafel slope values are close to the expected ones from the relationship:

$\beta \mathrm{nF} / 2.303 \mathrm{RT}$

where $\beta$ is the transfer coefficient, $\mathrm{n}$ the number of electrons, $\mathrm{R}$ the universal gas constant and $\mathrm{T}$ the temperature. Such slope values are valid for the reaction scheme given above, with either the Volmer (equation 1) or the Heyrovsky reaction (equation 2) as the RDS and the adsorption of reagent occurring by a Langmuir type isotherm. The large value obtained for the apparent free energy of activation in the RDS $\left(150 \mathrm{~kJ} \mathrm{~mol}^{-1}\right)$, points to that calculated by Bockris and Mathews for the HER on $\mathrm{Hg}$ in acid medium (i.e., $210 \mathrm{~kJ} \mathrm{~mol}^{-1}$ ). ${ }^{23}$ This value has been related to the formation of the activated complex shown by equation (4) of the Introduction section that, in turn, corresponds to the Volmer reaction (equation (1)) in the mechanism presented in the same section.

\section{The Oxygen Evolution Reaction}

In this work, the OER occurring at the positive limit of 
potential was also studied by steady-state polarization curves. The same procedure described above for the HER was used here, but using a different range of anodic current density values. The ohmic drop was also compensated by the interruption technique. It should be mentioned that Michaud et al. and Serrano et al. reported a slow formation of peroxydisulfuric acid $(<5 \%)$ under extreme anodic conditions $\left(30 \mathrm{~mA} \mathrm{~cm}^{2}\right) .{ }^{25,26}$ However, experiments carried out using $0.5 \mathrm{~mol} \mathrm{~L}^{-1} \mathrm{HClO}_{4}$ as the supporting electrolyte yielded identical results as those from $\mathrm{H}_{2} \mathrm{SO}_{4}$ solutions thus proving that the only product formed in the present case is $\mathrm{O}_{2}$.

The Tafel plots obtained for the different temperatures are presented in Figure 4 together with the response at $25^{\circ} \mathrm{C}$ of a $\mathrm{Pt}$ electrode under the same experimental conditions, for comparison. In this later case, the Tafel plot corresponds to the high-potential response of the OER on $\mathrm{Pt}$ with a slope value of approximately $120 \mathrm{mV} \mathrm{dec}^{-1}$.

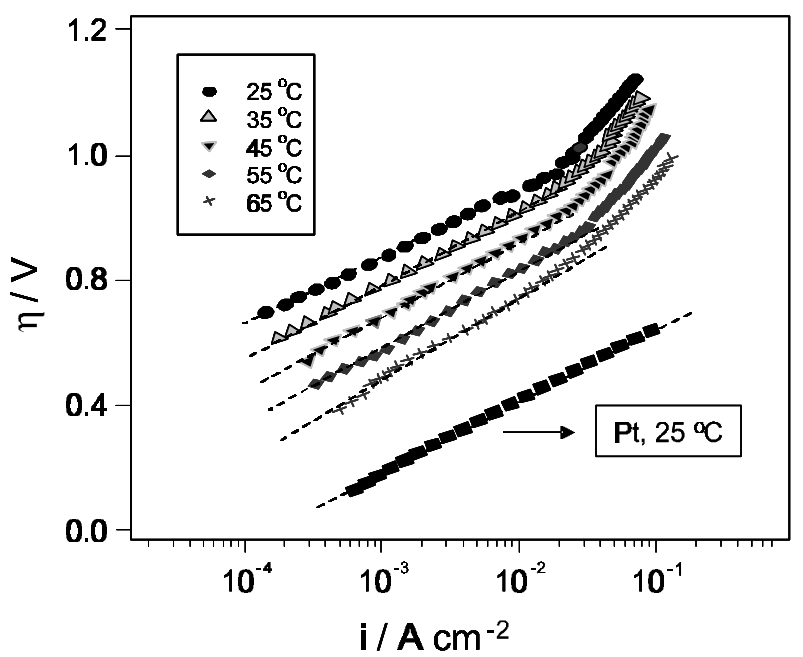

Figure 4. Tafel plots for the OER on the BDD electrode in $0.5 \mathrm{~mol} \mathrm{~L}^{-1}$ $\mathrm{H}_{2} \mathrm{SO}_{4}+0.5 \mathrm{~mol} \mathrm{~L}^{-1} \mathrm{Na}_{2} \mathrm{SO}_{4}$ at different temperatures. The bottom curve corresponds to $\mathrm{Pt}$ at $25{ }^{\circ} \mathrm{C}$ and is included for comparison.

The slopes obtained from the linear section of the curves recorded on BDD are collected in Table 2. The non-linear region of the plots in Figure 4 seems to indicate that either the reaction is approaching diffusion control, the instrument does not properly compensate the internal resistance of the BDD electrode or the electrode surface was deactivated for the extensive anodic polarization. Nevertheless, the Tafel slopes obtained for different temperatures are in agreement with those for $\mathrm{Pt}$ in the high overpotential region (near $120 \mathrm{mV} \mathrm{dec}^{-1}$ at $25^{\circ} \mathrm{C}$ ). However, on BDD it was not possible to observe a linear region with a slope of $60 \mathrm{mV} \mathrm{dec}{ }^{-1}$, that is characteristic for Pt at low overpotentials. This can be related with the high activation
Table 2. Tafel parameters for the OER on the BDD electrode in acid media

\begin{tabular}{cccc}
\hline $\mathrm{T} /{ }^{\circ} \mathrm{C}$ & $\mathrm{b}_{\text {exp }} / \mathrm{mV} \mathrm{dec}^{-1}$ & $\mathrm{i}_{\mathrm{o}} / \mathrm{A} \mathrm{cm}^{-2}$ & $\Delta \mathrm{G}^{\#} / \mathrm{kJ} \mathrm{mol}^{-1}$ \\
\hline 25 & 130 & $9.01 \times 10^{-8}$ & \\
35 & 158 & $4.49 \times 10^{-7}$ & \\
45 & 170 & $1.90 \times 10^{-6}$ & 106 \\
55 & 180 & $5.54 \times 10^{-6}$ & \\
65 & 230 & $1.54 \times 10^{-5}$ & \\
$\mathrm{Pt}$ & 140 & $2.89 \times 10^{-4}$ & 47 \\
\hline
\end{tabular}

energies required for the formation of intermediate adsorbed species on this surface (see below).

The corresponding values of $i_{o}$ at each temperature were determined as before considering now the value of $\mathrm{E}_{\mathrm{o}}$ as $1.229 \mathrm{~V}$ and are also presented in Table $2 .{ }^{27}$ To analyze these values, the Arrhenius plot shown in Figure 5 was constructed. The apparent energy of activation obtained from such plot is $106 \mathrm{~kJ} \mathrm{~mol}^{-1}$, a value somewhat higher than that previously reported for the OER on Pt in acid medium $^{24}$ (i.e., $47 \mathrm{~kJ} \mathrm{~mol}^{-1}$ ). All these parameters for the OER are collected in Table 2 and are in agreement with the mechanistic pathway for the OER shown in the Introduction section with the adsorption step (equation 6) being the RDS.

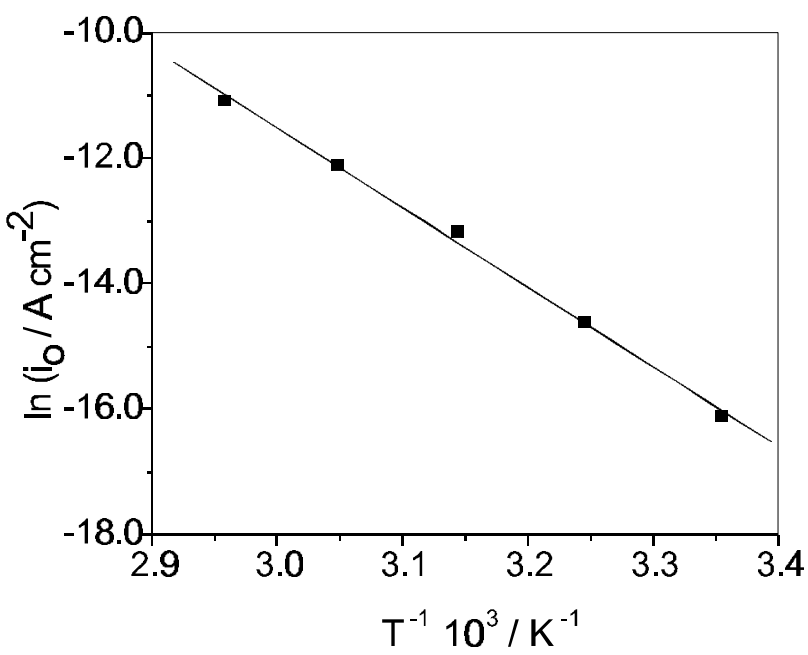

Figure 5. Arrhenius plot for the OER on the BDD electrode with data taken from Figure 4.

\section{Conclusions}

Comparison of apparent energies of activation measured here for the HER and the OER with previous published values for other type of electrodes indicates that the adsorption processes are responsible for the wide electrochemical window of the BDD electrode in aqueous 
medium. Interactions between water molecules and the electrode surface are strongly inhibited and the energies involved are, consequently, very high. Both mechanisms for the hydrogen and the oxygen evolution reactions have an initial adsorption step that becomes rate determining and extremely slow on BDD surfaces.

As a consequence of this, BDD electrodes can be very useful for electrolyses carried out at extreme potential values with very little interference from the water decomposition reactions. Additionally, such reduced interactions between the surface and the water molecules might be responsible for the extremely low capacitive currents measured in voltammetric experiments. This makes the BDD electrode an ideal candidate for electroanalytical applications in very dilute solutions. Furthermore, the enhanced anodic stability of aqueous electrolytes on this material allows its use for the oxidation processes that are often required when investigating complex organic molecules like pesticides and biological compounds.

\section{Acknowledgements}

The authors wish to acknowledge CNPq for the financial support and the Centre Suisse de Electronique et de Microtechnique SA, Neuchatêl, Switzerland, for providing the boron doped diamond electrodes.

\section{References}

1. Spears, K.E.; Dismukes, E.J.P.; Synthetic Diamond - Emerging CVD Sci. and Tec.; John Wiley and Sons: New York, 1994.

2. Spears, K.E.; J. Am. Ceramic Soc. 1989, 72, 171.

3. Terometskaya, I.G.; Varnin, V. P.; Fedoseev, D.V.; Bulletin Acad. Sci. USSR Div. Chem. Science 1984, 33, 1724.

4. Zhang, R. J.; Lee, S.T.; Lam, Y.W.; Diamond Relat. Mater. 1996, 5, 1288.

5. Varnin, V.P.; Carbon 1990, 28, 795.

6. Fisher, V.; Gandini, D.; Laufer, S.; Blank E.; Comninellis, C.; Electrochim. Acta 1998, 44, 521.

7. Li, L.F.; Totir, D.A.; Vinokur, N.; Miller, B.; Chottiner, G.; Evans, E.A.; Angus, J.C.; Scherson, D.A.; J. Electrochem. Soc. 1998, 145, L85.

8. Bachmann, P. K.; Messier, R.; Chem. Eng. News 1989, 67, 24.

9. Wu, Z.Y.; Yano, T.; Tryk, D.A.; Hashimoto, K.; Fujishima, A.; Chem. Lett. 1998, 503.
10. Li, L.F.; Totir, D.A.; Miller, B.; Chottiner, G.; Argoitia, A.; Angus, J.C.; Scherson, D.A.; J. Am. Chem. Soc. 1997, 119, 7875 .

11. Perret, A.; Haenni, W.; Niedermann, P.; Skinner, N.; Comninellis, C.; Gandini, D.; Electrochem. Soc. Proceedings 1997, 97, 275.

12. Swain, G.M.; J. Electrochem. Soc. 1994, 141, 3382.

13. Swain, G.M.; Adv. Mater 1994, 6, 388.

14. Okano, K.; Koizumi, S.; Silva, S.R.P.; Amaratunga, G.A.J.; Nature 1996, 381, 140.

15. Iwaki, M.; Sato, S.; Takahashi, K.; Sakairi, H.; Nucl. Instrum. Methods 1983, 209, 1129.

16. Avaca, L.A.; Codognoto, L.; Machado, S.A.S.; Diamond Relat. Mater 2002, 11, 1670.

17. Avaca, L.A.; Codognoto, L.; Machado, S.A.S; Diamond Mater. VII - The Electrochem. Soc. Proccedings Series; Swain, G. M.; Davidson, J. L.; Angus, J. C.; Ando, T.; Brown, W. D., eds.; Pennington, 2001, 7, 34.

18. Codognoto, L.; Machado, S.A.S.; Avaca, L.A.; J. Appl. Electrochem. (in press).

19. Zhang, Y.R.; Asahina, S.; Yoshihara, S.; Shirakashi T.; J. Electrochem. Soc. 2002, 149, H179.

20. Pastor-Moreno, G.; Riley, D.; Electrochem. Commun 2002, 4, 218.

21. Yoshimura, M.; Honda, K.; Kondo, T.; Uchikado, R.; Einaga, Y.; Rao, T.N.; Tryk, D.A.; Fujishima, A.; Diamond Relat. Mater 2002, $11,67$.

22. Correia, A.N.; Machado, S.A.S.; Electrochim. Acta 1998, 43, 367.

23. Mathews, D.B.; Bockris, J. O’M. In Modern Aspects of Electrochem; Bockris, J. O’M.; Conway, B. E., eds.; Plenum Press: New York, 1971, p. 242.

24. Damjanovic, A.; Dey, A.; Bockris, J. O’M.; Electrochim. Acta 1966, 11, 791.

25. Michaud, P. A.; Mahé, E.; Haenni, W.; Perret, A.; Comninellis, C.; Electrochem. Solid-State Lett. 2000, 3, 77.

26. Serrano, K.; Michaud, P. A.; Comninellis, C.; Savall A.; Electrochim. Acta 2002, 48, 431.

27. Bockris, J. O’M.; Conway, B.E. In Modern Aspects of Electrochem; Bockris, J. O’M.; Conway, B. E., eds.; Plenum Press: New York, 1969, p. 372.

Received: November 27, 2002 Published on the web: October 15, 2003

FAPESP helped in meeting the publication costs of this article. 